SITZUNGSBERICHTE DER SÄCHSISCHEN AKADEMIE DER WISSENSCHAFTEN ZU LEIPZIG

Mathematisch-naturwissenschaftliche Klasse

Band 110 . Heft 7

ROLF EMMRICH

\title{
ZWISCHEN LEBEN UND TOD
}

Ärztliche Probleme der Thanatologie

Mit 2 Abbildungen und 4 Tabellen

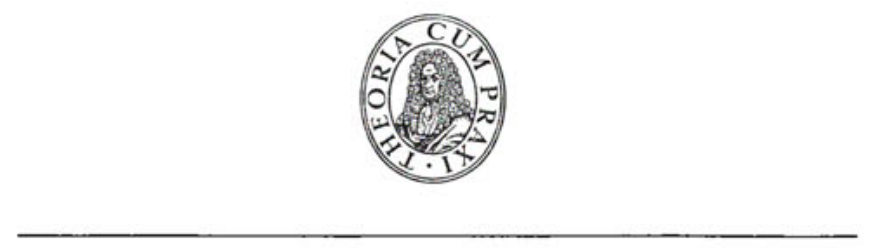

AKADEMIE-VERLAG - BERLIN

1974 
Vorgetragen in der Sitzung am 15, Oktober 1973

Manuskript eingeliefert am 20. November 1973

Druckfertig erklärt am 15. Juli 1974

Erschienen im Akademie-Verlag, 108 Berlin, Leipziger Str. 3-4

(c) Akademie-Verlag, Berlin, 1974

Lizenznummer : $202 \cdot 100 / 574 / 74$

Gesamtherstellung: VEB Druckhaus „Maxim Gorki“, 74 Altenburg

Bestellnummer: $7620012(2027 / 110 / 7) \cdot$ LSV 2005

Printed in GDR

EVP 3,50 